Original Research

\title{
Intra- and interrater reliability of the 'lumbar-locked thoracic rotation test' in competitive swimmers ages 10 through 18 years
}

\author{
Stef Feijen ${ }^{a}$, Kevin Kuppens ${ }^{a}$, Angela Tate ${ }^{b}$, Isabel Baert ${ }^{a}$, Thomas Struyf ${ }^{c}$, Filip Struyf ${ }^{\text {a, * }}$ \\ ${ }^{a}$ Department of Rehabilitation Sciences and Physiotherapy, Faculty of Medicine and Health Sciences, University of Antwerp, Belgium \\ ${ }^{\mathrm{b}}$ Department of Physical Therapy, Arcadia University, Glenside, PA, USA \\ ${ }^{\mathrm{c}}$ Healthcare-associated Infections \& Antimicrobial Resistance, Scientific Institute of Public Health, Brussels, Belgium
}

\section{A R T I C L E I N F O}

\section{Article history:}

Received 22 December 2017

Received in revised form

19 March 2018

\section{Keywords:}

Reliability

Swimming

Thoracic spine rotation

Range of motion

\begin{abstract}
A B S T R A C T
Objectives: Measuring thoracic spine mobility can be of interest to competitive swimmers as it has been associated with shoulder girdle function and scapular position in subjects with and without shoulder pain. At present, no reliability data of thoracic spine mobility measurements are available in the swimming population. This study aims to evaluate the within-session intra- and interrater reliability of the "lumbar-locked rotation test" for thoracic spine rotation in competitive swimmers aged 10 to 18 years. This reliability study is part of a larger prospective cohort study investigating potential risk factors for the development of shoulder pain in competitive swimmers.

Design: Within-session, intra- and inter-rater reliability.

Setting: Competitive swimming clubs in Belgium.

Participants: 21 competitive swimmers.

Main outcome measures: Intra- and inter-rater reliability of the lumbar-locked thoracic rotation test. Results: Intraclass correlation coefficients (ICCs) ranged from 0.91 (95\% CI 0.78 to 0.96 ) to 0.96 (0.89 $-0.98)$ for intra-rater reliability. Results for inter-rater reliability ranged from $0.89(0.72-0.95)$ to 0.86 (0.65-0.94) respectively for right and left thoracic rotation.

Conclusion: Results suggest good to excellent reliability of the lumbar-locked thoracic rotation test, indicating this test can be used reliably in clinical practice.
\end{abstract}

(c) 2018 Elsevier Ltd. All rights reserved.

\section{Introduction}

Shoulder pain is the most common orthopedic injury in competitive swimming, with the prevalence reported as high as 91\% (McMaster, 1999; Wanivenhaus, Fox, Chaudhury, \& Rodeo, 2012). Most of these injuries and complaints are due to repetitive micro trauma or overuse as the upper extremity plays a major role in generating the propulsive force (McMaster, 1996; Pink \& Tibone, 2000). Nevertheless, swimming is defined as both an upperextremity- and spine-intensive sport (Cole et al., 1996), and requires sufficient mobility of the spine to facilitate body roll and breathing at both sides (Micheli, Stein, O'Brien, \& d'Hemecourt, 2016).

Mobility can be considered as the variation in range of

\footnotetext{
* Corresponding author. Faculty of Medicine and Health Sciences, University of Antwerp, Belgium, Universiteitsplein 1, 2610 Wilrijk, Belgium.

E-mail address: Filip.struyf@uantwerpen.be (F. Struyf).
}

movement which is possible in the joint of a normal individual (Beighton, Solomon, \& Soskolne, 1973). Thoracic spine mobility is especially of importance during the recovery phase of freestyle swimming (Micheli et al., 2016), which is characterized by a rolling movement of minimum $45^{\circ}$ along the longitudinal axis of the body (Colwin, 2002; Johnson, Gauvin, \& Fredericson, 2003). Decreased thoracic spine rotation during this phase could lead to a lack in body roll, hereby requiring a larger glenohumeral horizontal abduction motion of the swimmer and increase mechanical stress on the shoulder (Johnson et al., 2003).

To our knowledge, there is limited literature available specific on the influence of thoracic spine mobility on shoulder symptoms in swimmers. However, it has been suggested that restrictions in this mobility of the thoracic spine may impair functioning of anatomically related regions, such as the shoulder, and predispose it to pain or injury (Sueki, Cleland, \& Wainner, 2013). Research focusing on this regional interdependence (RI) has shown that individuals with restricted thoracic spine mobility tend to experience a decrease in shoulder function, symptoms of shoulder impingement and pain 
(Edmondston et al., 2012; Meurer, Grober, Betz, Decking, \& Rompe, 2004; Theodoridis \& Ruston, 2002). In addition, patients with signs of impingement seem to present more often with thoracic hyperkyphosis compared to healthy subjects (Gray \& Grimsby, 2004; Grimsby \& Gray, 1997; Pollard \& Fernandez, 2004). Furthermore, previous research suggests that a posture of increased thoracic kyphosis, which is often seen in competitive swimmers (Ferrell, 1999), not only limits mobility of the thoracic spine itself (Otoshi et al., 2014) but also influences glenohumeral range of motion (ROM), scapular muscle strength and scapular kinematics in subjects with and without shoulder pain (Barrett, O'Keeffe, O'Sullivan, Lewis, \& McCreesh, 2016; Kebaetse, McClure, \& Pratt, 1999).

Reliably quantifying thoracic spine rotation in competitive swimmers can be of great importance to prevent shoulder injury (Johnson, Kim, Yu, Saliba, \& Grindstaff, 2012). Methodologies that are commonly used in clinical setting are the half-kneeling rotation test, the seated rotation test and the lumbar-locked rotation test (Johnson et al., 2012). Whereas all three methods have been shown reliable in healthy adults between 18 and 45 years old, use of the lumbar-locked rotation test may be more appropriate in competitive swimmers as the quadruped position limits movement of the lumbar spine, providing a more isolated assessment at thoracic level (Johnson et al., 2012).

Measurement of thoracic spine rotation in this quadruped position has both been shown reliable (Johnson et al., 2012) and valid in healthy adults (Bucke et al., 2017; Hwang et al., 2017). However, this method has not been tested in young competitive swimmers who may exhibit greater thoracic mobility both due to differences in age (Aebi, Gunzburg, \& Spzpalski, 2005) and the repetitive nature of spine movements during swimming (Johnson et al., 2012; Pollard \& Fernandez, 2004). Since spinal rotation is essential to the swimming stroke (Micheli et al., 2016), a reliable method for measurement in youth competitive swimmers is needed. Therefore, the purpose of this study is to evaluate the within-session intra- and inter-rater reliability of the lumbar-locked rotation test for thoracic spine rotation in competitive swimmers ages 10 through 18 years.

\section{Methods}

This intra- and interrater reliability study was performed following the Guidelines for Reporting Reliability and Agreement Studies (GRRAS) (Kottner et al., 2011) and examined the reliability of the lumbar-locked rotation test within a larger prospective cohort study.

\subsection{Participants}

21 swimmers, 9 women and 12 men, participated in this study $\quad($ age $=13.52 \pm 1.57 \mathrm{y}, \quad$ height $=166.43 \pm 9.94 \mathrm{~cm}$, weight $=53.57 \pm 12.40 \mathrm{~kg}$ ). Participants were considered eligible if they trained for an average of at least $4 \mathrm{~h}$ per week, were aged between 10 and 18 years and were free from any known pathologic condition of the spine, ribs or shoulder within the past 6 months. Swimmers needed to be active in competitive clubs in Flanders, Belgium. Participants were excluded if they suffered from shoulder pain at the start of the study, had shoulder pain one month prior to the onset of the study or if they had shoulder surgery or a major shoulder trauma 12 months before onset of the study. Subjects suffering from any known neurological, systemic, metabolic, rheumatic or cardiovascular disease were also excluded.

\subsection{Design}

Prior to the study, both rater 1 (SF, master in Rehabilitation
Sciences and Physiotherapy with 2 years of clinical experience) and rater 2 (JVDL, bachelor in Rehabilitation Sciences and Physiotherapy) were trained by an experienced physiotherapist (KK, master in Rehabilitation Sciences and Physiotherapy with over 10 years of clinical experience). During this 2-h training session, the raters were instructed to perform accurate measurements of thoracic rotation by the lumbar-locked rotation test procedure (Johnson \& Grindstaff, 2010). A fluid-filled bubble inclinometer was used during this procedure to measure thoracic rotation ROM (Plurimeter, Dr. Rippstein, Switzerland).

During the study, measurements of each individual participant were carried out on the same day, at the local swimming pool. Participants received no formal warm-up but were familiarized with the movement of thoracic rotation before data collection. The order of rater and primary side of rotation were standardized throughout the entire study. Raters were blinded to each other's findings. Both sides of thoracic rotation were measured independently.

\subsection{Procedure}

First, swimmers completed a baseline questionnaire regarding demographics, anthropometric features, swim training and injury history. Next, both raters obtained the lumbar-locked thoracic rotation test twice per swimmer. During the first test (performed by rater 1 ) the swimmer conducted three consecutive repetitions of thoracic rotation to each side. Following a 30-s rest period, this was repeated by the same rater. At the end of the prospective screening session, the entire procedure was then repeated by the second rater.

\subsection{Lumbar-locked rotation test}

To measure the participant's thoracic rotation mobility, the protocol of the lumbar-locked thoracic rotation test was adapted as previously described by Johnson and Grindstaff (2010). During this test, the participant was placed in a 4-point kneeling position and instructed to sit back on the heels, placing the elbows in front of and in contact with the knees while keeping the forearms straight ahead. Next, the examiner placed the inclinometer on the spine over the interspinous space at T1-T2 level. This was indicated as the starting position, marked as $0^{\circ}$ on the inclinometer. The exact location of the interspinous space at T1-T2 level was determined by palpating from the participant's cervical spine during the 4-point kneeling position. Next, the participant was instructed to grasp his or her neck (Fig. 1a) and slowly rotate the thoracic spine ipsilateral without allowing the buttocks to come off the feet or extending the lumbar spine (Fig. 1b). By grasping the neck, the participants were informed to keep the head as much as possible aligned with the rotation of the thoracic spine. To measure rotation to the contralateral side, the contralateral hand was used to grasp the neck and the same procedure was followed. The inclinometer was held steady against the spine through the entire movement. Oral feedback was provided to ensure compliance. At the end of movement, the degree indicated by the pointer on the inclinometer was read and noted by the examiner.

Criteria during rotation movement that would result in a failed test and repeating the movement were inability to take the quadruped position (loss of pelvis, hip, or knee flexion); loss of lumbar spine position; scapular retraction; loss of upper extremity position both unilaterally (aberrant elbow angle or inability to keep the hand on the back of the neck) or bilaterally (inability to keep the contralateral arm on the table) (Johnson \& Grindstaff, 2010; Johnson et al., 2012). 
a)

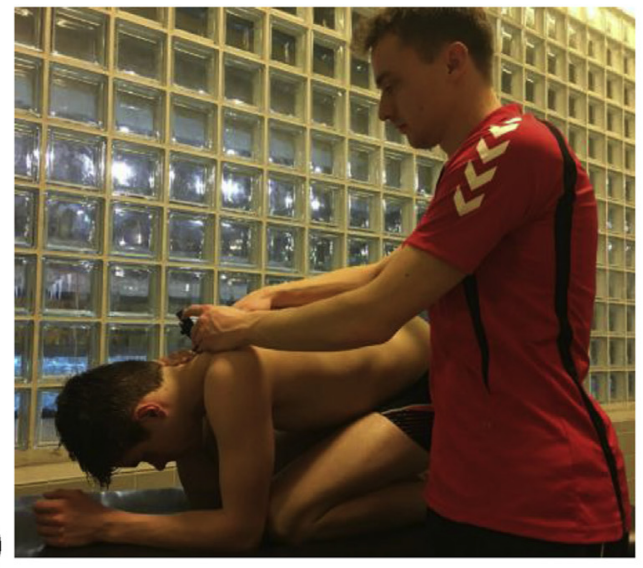

b)

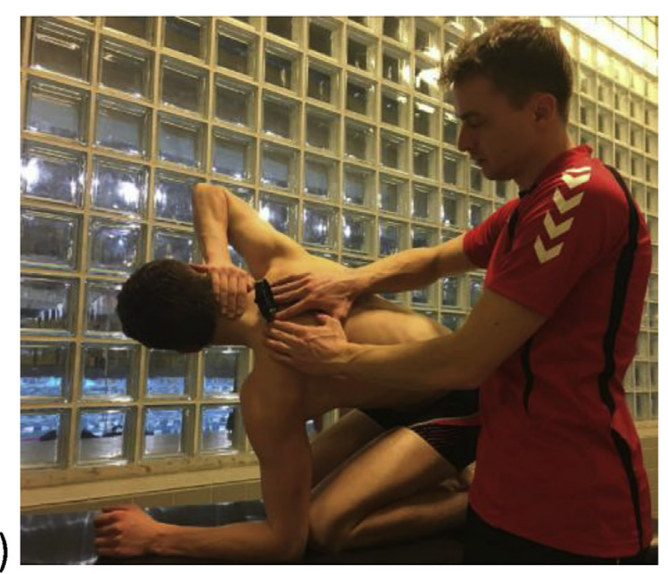

Fig. 1. a) Beginning position of the lumbar-locked rotation test for right thoracic rotation, b) ending position of the lumbar-locked rotation test for right thoracic rotation.

Table 1

Participant demographics given as mean ( \pm standard deviation) or the frequency.

\begin{tabular}{llll}
\hline Characteristics & Female $\mathrm{N}=9$ & Male $\mathrm{N}=12$ & Total $\mathrm{N}=21$ \\
\hline Age $(\mathrm{y})$ & $13.00(1.41)$ & $13.92(1.62)$ & $13.52(1.57)$ \\
Age started competition $(\mathrm{y})$ & $10.78(2.22)$ & $10.25(2.05)$ & $10.48(2.09)$ \\
Height $(\mathrm{cm})$ & $159.22(7.69)$ & $171.83(7.89)$ & $166.43(9.94)$ \\
Weight $(\mathrm{kg})$ & $48.0(12.18)$ & $57.75(11.29)$ & $53.57(12.40)$ \\
Arm span $(\mathrm{cm})$ & $159.61(7.81)$ & $176.63(11.01)$ & $169.33(12.87)$ \\
Weekly swim sessions & $4.33(1.32)$ & $4.50(1.24)$ & $4.43(1.25)$ \\
Previous injury (N) & 2 & 8 & 10 \\
Right hand dominance $(\mathrm{N})$ & 9 & 10 & 19 \\
\hline
\end{tabular}

$\mathrm{Y}=$ years; $\mathrm{cm}=$ centimeter; $\mathrm{kg}=$ kilogram; $\mathrm{N}=$ number of subjects.

\subsection{Statistical analysis}

Mean values were used for statistical analysis in SPSS software (version 24 for Windows) as these provided the greatest measurement stability (Heneghan, Hall, Hollands, \& Balanos, 2009). All
Table 3

Mean values ( \pm standard deviation) of both raters' six trials per side of rotation (used for inter-rater reliability).

\begin{tabular}{llll}
\hline & & Right & Left \\
\hline Lumbar-locked rotation test $\left(^{\circ}\right)$ & Rater 1 & $68.30 \pm 12.84$ & $63.52 \pm 14.98$ \\
& Rater 2 & $66.91 \pm 14.71$ & $63.04 \pm 13.73$ \\
\hline
\end{tabular}

variables were tested for normality using the Shapiro-Wilk test $(p>0.05)$. Within-session inter-rater reliability of the lumbarlocked rotation test was assessed using the intraclass correlation coefficient (ICC) model 2,6 (2-way random-effects model, absolute agreement) both for the left and right side of rotation. This model was used as the analysis is generalizable to other raters with similar characteristics (Shrout \& Fleiss, 1979; Weir, 2005). Inter-rater reliability was calculated using the mean values of all six trials per side of rotation. Within-session intra-rater reliability was assessed using an ICC model 3,3 (2-way mixed-effects model) (Shrout \& Fleiss, 1979). Here, the average values of the first and second three trials were compared within both raters for each side of rotation. Finally, to calculate the measurement error associated with the lumbarlocked rotation test both Standard Error of Measurement (SEM = SD $x \sqrt{ }(1-$ ICC $))$ and Minimal Detectable Change at the 95\% confidence level $\left(\mathrm{MDC}_{95}=\mathrm{SEM} \times 1.96 \times \sqrt{ } 2\right)$ were used for both the intra- and inter-rater reliability coefficients (McKenna, Cunningham, \& Straker, 2004; Weir, 2005). Reliability coefficients were interpreted as follows: less than 0.50: poor; between 0.50 and 0.75: moderate; between 0.76 and 0.90: good; and over 0.90 : excellent (Portney \& Watkins, 2013).

\section{Results}

Demographic characteristics of the subjects are presented in Table 1 . This study comprised 9 (43\%) female and 12 (57\%) male swimmers. Participants' age ranged from 10 to 18 years, with a mean age of $13.52( \pm 1.57)$. Subjects presented with a mean height of $166.43 \mathrm{~cm}( \pm 9.94)$ and weight of $53.57 \mathrm{~kg}( \pm 12.40)$. All swimmers were active in competitive clubs in Belgium and performed, on average, $4.43( \pm 1.25)$ swimming sessions per week. Mean values ( \pm standard deviations) of the lumbar-locked rotation tests used for within-session intra- and inter-rater reliability analyses are presented in Tables 2 and 3 respectively. Table 4 represents the intrarater and inter-rater ICC values with their 95\% confidence interval (CI).

Within-session inter-rater reliability analysis of the lumbarlocked rotation test showed ICC values between 0.86 (95\% CI 0.65 to 0.94 ) for left thoracic rotation and 0.89 (95\% CI 0.72 to 0.95 ) for right thoracic rotation. This reliability analysis was conducted using both raters' mean values of all six trials for each side of rotation. The presented confidence intervals of the ICCs determine the range in which the true ICC value will lie with $95 \%$ confidence on repeated measurements. Intra-rater reliability within rater 1 ranged from 0.91 ( $95 \%$ CI 0.78 to 0.96 ) to 0.96 ( $95 \%$ CI 0.89 to 0.98 ) for right and left thoracic rotation respectively. Rater 2 showed intra-rater ICCs of 0.95 for both left ( $95 \%$ CI 0.88 to 0.98 ) and right (95\% CI 0.86 to 0.98 ) thoracic rotation of the lumbar-locked rotation test. The mean

Table 2

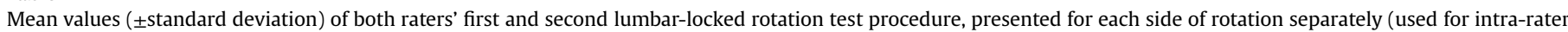
reliability).

\begin{tabular}{|c|c|c|c|c|c|}
\hline & & \multicolumn{2}{|l|}{ Rater 1} & \multicolumn{2}{|l|}{ Rater 2} \\
\hline & & Procedure 1 & Procedure 2 & Procedure 1 & Procedure 2 \\
\hline \multirow[t]{2}{*}{ Lumbar-locked rotation test $\left({ }^{\circ}\right)$} & Right & $68.44 \pm 12.80$ & $68.16 \pm 13.96$ & $66.79 \pm 14.45$ & $67.02 \pm 15.75$ \\
\hline & Left & $63.56 \pm 14.80$ & $63.49 \pm 15.81$ & $63.57 \pm 14.22$ & $62.51 \pm 13.92$ \\
\hline
\end{tabular}


Table 4

Within-session intra- (ICC 3,3) and inter-rater reliability (ICC 2,6).

\begin{tabular}{|c|c|c|c|c|c|c|c|}
\hline & & \multicolumn{3}{|l|}{ Right side } & \multicolumn{3}{|l|}{ Left side } \\
\hline & & ICC (95\% CI) & $\operatorname{SEM}\left({ }^{\circ}\right)$ & $\mathrm{MDC}_{95}\left(^{\circ}\right)$ & ICC $(95 \% \mathrm{CI})$ & $\operatorname{SEM}\left({ }^{\circ}\right)$ & $\mathrm{MDC}_{95}\left(^{\circ}\right)$ \\
\hline \multirow[t]{2}{*}{ Intra-rater } & Rater 1 & $0.91(0.78,0.96)$ & 3.80 & 10.56 & $0.96(0.89,0.98)$ & 3.18 & 8.81 \\
\hline & Rater 2 & $0.95(0.86,0.98)$ & 3.45 & 9.56 & $0.95(0.88,0.98)$ & 3.10 & 8.59 \\
\hline Inter-rater & Rater 1-2 & $0.89(0.72,0.95)$ & 4.41 & 12.22 & $0.86(0.65,0.94)$ & 5.02 & 13.91 \\
\hline
\end{tabular}

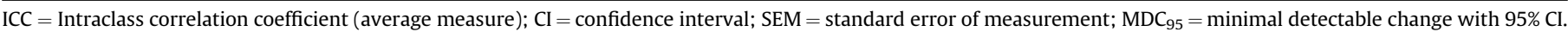

of three different trials was used to calculate these ICCs. The SEMs and $\mathrm{MDC}_{95}$ values of both the intra- and inter-rater reliability are also presented in Table 4.

\section{Discussion}

To our knowledge, reliability of the lumbar-locked rotation test has not yet been investigated in young competitive swimmers. The aim of this study was to assess the reliability of this test to measure ROM of thoracic rotation in competitive swimmers ages 10 through 18 years. ICCs indicated that the lumbar-locked rotation test is indeed a reliable measurement tool to assess this range of motion, both within and between raters (Portney \& Watkins, 2013). Intrarater ICC values suggest excellent reliability within both rater 1 (ICC 0.91 to 0.96 ) and rater 2 (ICC 0.95). In addition, results suggest good inter-rater reliability of the lumbar-locked rotation test with ICCs ranging from 0.86 (95\% CI 0.65 to 0.94 ) to 0.89 (95\% CI 0.72 to $0.95)$.

SEM values are used to indicate the precision of a single measurement score. Calculated SEMs range from $3^{\circ}$ to $4^{\circ}$ for intra-rater reliability analyses. Inter-rater reliability presents with SEMs between $12^{\circ}$ and $14^{\circ}$. These values could aid the clinician in estimating the clinical value of its measurement. SEMs can also be used to calculate $\mathrm{MDC}_{95}$. $\mathrm{MDC}_{95}$ defines the amount of change that must be achieved in the measurement to be $95 \%$ sure that this change is larger than the measurement error. MDCs ranged from 9 to $10^{\circ}$ for intra-rater reliability and $12-14^{\circ}$ for inter-rater reliability analysis.

Current results fall in line with those of Johnson et al. (2012), who found good intra- and inter-rater reliability of the lumbarlocked rotation test in 46 healthy adults. Comparison should be made with caution, though, as our sample was consistently younger. In addition, previously reported normative data of thoracic rotation measurements in healthy children between 10 and 16 years old showed significantly lower ROM values for both directions of rotation compared to our data (Mellin \& Poussa, 1992). While keeping in mind that alternative measurement methods and instruments can lead to discrepancy in the results, some of these differences between our and previous research may be explained by the characteristics of the population. Swimmers can perform up to 10 stroke cycles each $25 \mathrm{~m}$ (Allegrucci, Whitney, \& Irrgang, 1994). Training at $10000 \mathrm{~m}$ a day would include 4000 shoulder revolutions. If a swimmer breathes every three strokes - bilateral breathing is encouraged - he or she would rotate the thoracic spine for about 1333 times during a day of training. These repetitive rotations, in combination with thoracic rotation that occurs during the non-breathing strokes, could lead to a greater mobility of the thoracic spine compared to healthy non-swimmers.

A variety of musculoskeletal impairments, such as scapular dyskinesia and decreased or increased glenohumeral ROM, have previously been shown to relate to shoulder pain in swimmers (Struyf, Tate, Kuppens, Feijen, \& Michener, 2017). As mentioned above, such impairments have also been associated with the thoracic spine's posture, position and mobility (Barrett et al., 2016; Kebaetse et al., 1999; Meurer et al., 2004). Therefore, involvement of the thoracic spine in the development of the swimmer's shoulder pain cannot be excluded. In addition, rotation of the thoracic spine seems to play an important role during the swimming stroke by enabling the body to roll along its longitudinal axis (Micheli et al., 2016). Lack of this body roll could increase mechanical stress on the shoulder and lead to swimming stroke errors, increasing the risk for shoulder pain (Virag, Hibberd, Oyama, Padua, \& Myers, 2014). A reliable measurement of the swimmer's thoracic spine rotation thus seems of great importance in order to help prevent the onset of shoulder injuries.

Results of this study suggest that the lumbar-locked thoracic rotation test can be used reliably in a clinical setting. However, potential limitations should be addressed while interpreting these results. First, the fixed order of rater and primary side of rotation used throughout the study might have led to potential learning and or mobilization effects. Although swimmers were not informed about their individual scores and familiarized with the test before data collection, the high amount of repetitions used in this design may still have influenced the swimmer's performance. Next to that, raters were not blinded for their own measurements, possibly limiting intra-rater reliability results. Although both raters underwent the same training-procedure, differences in reliability might be explained by differences in skills or personal characteristics of both raters. Finally, issues in reliability studies using inclinometers are often related to holding the inclinometer correctly (Norkin \& White, 2016). By holding the inclinometer on the spine during the test, we could have influenced the participant's movement of thoracic rotation.

This study only examined competitive swimmers aged 10-18 years with no short-term history of injury. Therefore, our findings may not be generalized to people outside this population or age group or to people with spine injuries. In future studies, inclusion of participants with symptoms, a limited thoracic spine mobility and a greater age range could improve generalizability. Also randomization of order of rater and primary side of rotation might be recommended. Additionally, future research might explore other methods to accurately monitor the swimmer's thoracic rotation. For example, motion analysis based on video images of the swimmer's stroke biomechanics could be used to capture the swimmer's thoracic rotation in a more functional setting.

\section{Conclusion}

Results of this study suggest good to excellent within-session reliability (inter-rater ICCs 0.86 to 0.89 ; intra-rater ICCs 0.91 to 0.96 ) of the lumbar-locked rotation test, indicating this test can be used reliably in clinical practice. Further research is necessary to determine the validity and diagnostic accuracy of this measurement technique in competitive swimmers between ages of 10-18 years.

\section{Conflicts of interest}

None declared. 


\section{Ethical approval}

This study has been approved by the Committee for Medical Ethics UZA-UAntwerp (B300201630081). Subjects gave written informed consent prior to the work.

\section{Funding}

This research did not receive any specific grant from funding agencies in the public, commercial, or not-for-profit sector.

\section{Acknowledgments}

We would like to thank J. Van de Leur and J. Laureyssens for their assistance in performing the measurements. Furthermore, we would like to thank T. Struyf for his assistance in statistical analysis. This research did not receive any specific grant from funding agencies, commercial, or not-profit sectors. The authors declare that they have no conflict of interest.

\section{Appendix A. Supplementary data}

Supplementary data related to this article can be found at https://doi.org/10.1016/j.ptsp.2018.04.012.

\section{References}

Aebi, M., Gunzburg, R., \& Spzpalski, M. (2005). The aging spine. Berlin Heidelberg: Springer Verlag.

Allegrucci, M., Whitney, S. L., \& Irrgang, J. J. (1994). Clinical implications of secondary impingement of the shoulder in freestyle swimmers. Journal of Orthopaedic \& Sports Physical Therapy, 20(6), 307-318. https://doi.org/10.2519/ jospt.1994.20.6.307.

Barrett, E., O'Keeffe, M., O'Sullivan, K., Lewis, J., \& McCreesh, K. (2016). Is thoracic spine posture associated with shoulder pain, range of motion and function? A systematic review. Manual Therapy, 26, 38-46. https://doi.org/10.1016/ j.math.2016.07.008.

Beighton, P., Solomon, L., \& Soskolne, C. L. (1973). Articular mobility in an African population. Annals of the Rheumatic Diseases, 32(5), 413. https://doi.org/10.1136/ ard.32.5.413.

Bucke, J. M. B., Spencer, S. M. B., Fawcett, L. M. B., Sonvico, L. M. B., Rushton, A. M. E., \& Heneghan, N. R. P. M. (2017). Validity of the digital inclinometer and iPhone when measuring thoracic spine rotation. Journal of Athletic Training, 52(9), 820-825. https://doi.org/10.4085/1062-6050-52.6.05.

Cole, A., Campbell, D., Berson, D., Eagleston, R., Moschetti, M., \& Stratton, S. (1996). Swimming. In R. Watkins (Ed.), The spine in sports (1st ed., p. 362). St. Louis: Mosby.

Colwin, C. (2002). Breakthrough swimming: Human kinetics.

Edmondston, S. J., Ferguson, A., Ippersiel, P., Ronningen, L., Sodeland, S., \& Barclay, L. (2012). Clinical and radiological investigation of thoracic spine extension motion during bilateral arm elevation. Journal of Orthopaedic \& Sports Physical Therapy, 42(10), 861-669.

Ferrell, M. C. (1999). The spine in swimming. Clinics in Sports Medicine, 18(2), $389-393$.

Gray, J. C., \& Grimsby, O. (2004). Interrelationship of the spine, rib cage, and shoulder. In R. Donatelli (Ed.), Physical therapy of the shoulder (4th ed., pp. 133-185). Edinburgh: Churchill Livingstone.

Grimsby, O., \& Gray, J. (1997). Interrelation of the spine to the shoulder girdle. In R. Donatelli (Ed.), Physical therapy of the shoulder (pp. 95-129). New York: Churchill Livingstone.

Heneghan, N. R., Hall, A., Hollands, M., \& Balanos, G. M. (2009). Stability and intratester reliability of an in vivo measurement of thoracic axial rotation using an innovative methodology. Manual Therapy, 14(4), 452-455. https://doi.org/ 10.1016/j.math.2008.10.004.

Hwang, D., Lee, J. H., Moon, S., Park, S. W., Woo, J., \& Kim, C. (2017). The reliability of the nonradiologic measures of thoracic spine rotation in healthy adults. Physical Therapy Rehabilitation Science, 6(2), 65-70.

Johnson, J. N., Gauvin, J., \& Fredericson, M. (2003). Swimming biomechanics and injury prevention: New stroke techniques and medical considerations. The Physician and Sportsmedicine, 31(1), 41-46. https://doi.org/10.3810/ psm.2003.01.165.

Johnson, K. D., \& Grindstaff, T. L. (2010). Thoracic rotation measurement techniques: Clinical commentary. North American Journal of Sports Physical Therapy : NAJSPT, 5(4), 252-256.

Johnson, K. D., Kim, K. M., Yu, B. K., Saliba, S. A., \& Grindstaff, T. L. (2012). Reliability of thoracic spine rotation range-of-motion measurements in healthy adults. Journal of Athletic Training, 47(1), 52-60.

Kebaetse, M., McClure, P., \& Pratt, N. A. (1999). Thoracic position effect on shoulder range of motion, strength, and three-dimensional scapular kinematics. Archives of Physical Medicine and Rehabilitation, 80(8), 945-950.

Kottner, J., Audigé, L., Brorson, S., Donner, A., Gajewski, B. J. Hróbjartsson, A., ... Streiner, D. L. (2011). Guidelines for reporting reliability and agreement studies (GRRAS) were proposed. International Journal of Nursing Studies, 48(6), 661-671.

McKenna, L., Cunningham, J., \& Straker, L. (2004). Inter-tester reliability of scapular position in junior elite swimmers. Physical Therapy in Sport, 5(3), 146-155.

McMaster, W. C. (1996). Swimming injuries. An overview. Sports Medicine, 22(5), 332-336.

McMaster, W. C. (1999). Shoulder injuries in competitive swimmers. Clinics in Sports Medicine, 18(2), 349-359. vii.

Mellin, G., \& Poussa, M. (1992). Spinal mobility and posture in 8-to 16-year-old children. Journal of Orthopaedic Research, 10(2), 211-216.

Meurer, A., Grober, J., Betz, U., Decking, J., \& Rompe, J. D. (2004). BWS-mobility in patients with an impingement syndrome compared to healthy subjects-an inclinometric study. Zeitschrift für Orthopädie und ihre Grenzgebiete, 142(4), 415-420. https://doi.org/10.1055/s-2004-822821.

Micheli, L., Stein, C., O'Brien, M., \& d'Hemecourt, P. (2016). Spinal injuries and conditions in young athletes. New York, USA: Springer.

Norkin, C. C., \& White, D. J. (2016). Measurement of joint motion: A guide to goniometry. Philadelphia: FA Davis Company.

Otoshi, K., Takegami, M., Sekiguchi, M., Onishi, Y., Yamazaki, S., Otani, K., ... Konno, S. (2014). Association between kyphosis and subacromial impingement syndrome: LOHAS study. Journal of Shoulder and Elbow Surgery, 23(12), 300-307. https://doi.org/10.1016/j.jse.2014.04.010.

Pink, M. M., \& Tibone, J. E. (2000). The painful shoulder in the swimming athlete Orthopedic Clinics of North America, 31(2), 247-261.

Pollard, H., \& Fernandez, M. (2004). Spinal musculoskeletal injuries associated with swimming: A discussion of technique. Australasian Chiropractic and Osteopathy, 12(2), 72-80.

Portney, L., \& Watkins, M. (2013). Foundations of clinical research: Application to practice. Stamford, USA: Pearson Education Limited.

Shrout, P. E., \& Fleiss, J. L. (1979). Intraclass correlations: Uses in assessing rater reliability. Psychological Bulletin, 86(2), 420-428.

Struyf, F., Tate, A., Kuppens, K., Feijen, S., \& Michener, L. A. (2017). Musculoskeletal dysfunctions associated with swimmers' shoulder. British Journal of Sports Medicine, 51(10), 775-780. https://doi.org/10.1136/bjsports-2016-096847.

Sueki, D. G., Cleland, J. A., \& Wainner, R. S. (2013). A regional interdependence model of musculoskeletal dysfunction: Research, mechanisms, and clinical implications. Journal of Manual \& Manipulative Therapy, 21(2), 90-102. https://doi.org/ 10.1179/2042618612Y.0000000027.

Theodoridis, D., \& Ruston, S. (2002). The effect of shoulder movements on thoracic spine 3D motion. Clinical biomechanics, 17(5), 418-421.

Virag, B., Hibberd, E. E., Oyama, S., Padua, D. A., \& Myers, J. B. (2014). Prevalence of freestyle biomechanical errors in elite competitive swimmers. Sport Health 6(3), 218-224. https://doi.org/10.1177/1941738114527056.

Wanivenhaus, F., Fox, A. J., Chaudhury, S., \& Rodeo, S. A. (2012). Epidemiology of injuries and prevention strategies in competitive swimmers. Sport Health, 4(3), 246-251. https://doi.org/10.1177/1941738112442132.

Weir, J. P. (2005). Quantifying test-retest reliability using the intraclass correlation coefficient and the SEM. The Journal of Strength \& Conditioning Research, 19(1), 231-240. https://doi.org/10.1519/15184.1. 